\title{
Positive solutions for the third-order boundary value problems with the second derivatives
}

Yanping Guo ${ }^{1}$, Yujing Liu² and Yonhchun Liang ${ }^{1 *}$

\footnotetext{
* Correspondence: lycocean@163. com

${ }^{1}$ College of Electrical Engineering and Information, Hebei University of Science and Technology, Shijiazhuang, 050018, Hebei, PR China

Full list of author information is available at the end of the article
}

\section{Abstract}

By using the fixed-point index theory in a cone and defining a linear operator, we obtain the existence of at least one positive solution for the third-order boundary value problem with integral boundary conditions

$$
\left\{\begin{array}{l}
u^{\prime \prime \prime}(t)+f\left(t, u(t), u^{\prime \prime}(t)\right)=0, \quad t \in(0,1), \\
u(0)=0, \quad u^{\prime \prime}(0)=0, \quad u(1)=\int_{0}^{1} g(t) u(t) d t,
\end{array}\right.
$$

where $f:[0,1] \times R^{+} \times R^{-} \rightarrow R^{+}$is a nonnegative function. The associated Green's function for the above problem is also used, and a new reproducing cone also used.

Keywords: fixed-point index theory, Green?'?s function, positive solution, boundary value problem

\section{Introduction}

By eigenvalue criteria, Webb [1] obtained the existence of multiple positive solutions of a Hammerstein integral equation of the form

$$
u(t)=\int_{0}^{1} k(t, s) g(s) f(s, u(s)) d s,
$$

where $k$ can have discontinuities and $g \in L^{1}$. Then, some articles have studied different BVPs by this way (see [2-5]). Webb [4] introduced an unified method to study existence of at least one nonzero solution for higher order boundary value problems

$$
\left\{\begin{array}{c}
u^{(n)}(t)+g(t) f(t, u(t))=0, \quad 0<t<1, \\
u^{(n)}(0)=0, \quad 0 \leq k \leq n-2, \quad u(1)=\int_{0}^{1} u(s) d A(s) .
\end{array}\right.
$$

In 2010, Hao [5] considered the existence of positive solutions of the $n$ th-order BVP

$$
\left\{\begin{array}{c}
u^{(n)}(t)+\lambda a(t) f(t, u(t))=0, \quad t \in(0,1) \\
u(0)=u^{\prime}(0)=\cdots=u^{(n-2)}(0)=0, \quad u(1)=\int_{0}^{1} u(s) d A(s) .
\end{array}\right.
$$

Guo [6] studied the existence of positive solutions for the there-point boundary problem with the first-order derivative.

(c) 2012 Guo et al; licensee Springer. This is an Open Access article distributed under the terms of the Creative Commons Attribution License (http://creativecommons.org/licenses/by/2.0), which permits unrestricted use, distribution, and reproduction in any medium, provided the original work is properly cited. 


$$
\left\{\begin{array}{c}
x^{\prime \prime}+f\left(t, x, x^{\prime}\right)=0, \quad 0<t<1, \\
x(0)=0, \quad x(1)=\alpha x(\eta),
\end{array}\right.
$$

where $f$ is a nonnegative continuous function. In 2011, Zhao [7] studied third-order differential equations:

$$
x^{\prime \prime \prime}+f(t, x(t))=\theta, \quad t \in[0,1],
$$

subject to integral boundary condition of the form

$$
x(0)=\theta, \quad x^{\prime \prime}(0)=\theta, \quad x(1)=\int_{0}^{1} g(t) x(t) d t,
$$

where $f \in C([0,1] \times P, P)$.

In this article, we study the existence of positive solutions for the following boundary value problem

$$
\left\{\begin{array}{l}
u^{\prime \prime \prime}(t)+f\left(t, u(t), u^{\prime \prime}(t)\right)=0, \quad t \in(0,1) \\
u(0)=0, \quad u^{\prime \prime}(0)=0, \quad u(1)=\int_{0}^{1} g(t) u(t) d t .
\end{array}\right.
$$

The results are proved by applying the fixed point index theory in a cone and spectral radius of a linear operator. Unlike reference [7], the nonlinear part $f$ involves the second-order derivative and just satisfies Caratheodory conditions.

The following conditions are satisfied throughout this article:

$\left(H_{1}\right) f:[0,1] \times R^{+} \times R^{-} \rightarrow R^{+}$satisfies Caratheodory conditions, that is, $f(\cdot, u, v)$ is measurable for each fixed $u \in R^{+}, v \in R^{-}$, and $f(t, \cdot, \cdot)$ is continuous for a.e. $t \in[0,1]$. For any $r, r^{\prime}>0$, there exists $\varphi_{r, r^{\prime}}(t) \in L^{\infty}[0,1]$, such that $0 \leq f(t, u, v) \leq \varphi_{r, r^{\prime}}(t)$, where $(u, v) \in[0, r] \times\left[-r^{\prime}, 0\right]$, a.e. $t \in[0,1]$;

$\left(H_{2}\right) g \in L[0,1]$ is nonnegative, $b \in[0,1)$, where $b=\int_{0}^{1} s g(s) d s$.

\section{Preliminaries}

Lemma 2.1 [7]. Let $y \in L^{1}[0,1]$ and $y \geq 0$, the problem

$$
\left\{\begin{array}{l}
u^{\prime \prime \prime}(t)+\gamma(t)=0, \quad t \in(0,1), \\
u(0)=0, \quad u^{\prime \prime}(0)=0, \quad u(1)=\int_{0}^{1} g(t) u(t) d t
\end{array}\right.
$$

has a unique solution

$$
u(t)=\int_{0}^{1} H(t, s) \gamma(t) d s,
$$

where $H(t, s)=G(t, s)+\frac{t}{1-b} \int_{0}^{1} G(\tau, s) y(\tau) d \tau, \quad b=\int_{0}^{1} s g(s) d s$,

$$
G(t, s)=\left\{\begin{array}{c}
\frac{1}{2} t(1-s)^{2}-\frac{1}{2}(t-s)^{2}, 0 \leq s \leq t \leq 1 \\
\frac{1}{2} t(1-s)^{2}, \quad 0 \leq t \leq s \leq 1
\end{array}\right.
$$


Lemma 2.2. Let $y \in L^{1}[0,1]$ and $y \geq 0$, the unique solution of the boundary value problem (2.1) satisfies the following conditions: $u(t) \geq 0, u^{\prime \prime}(t) \leq 0$, for $t \in[0,1]$.

Proof. By Lemma 2.1, $u(t) \geq 0$. By differential equations $u^{\prime \prime}(t)+y(t)=0, t \in(0,1)$, we get

$$
\begin{gathered}
u^{\prime \prime}(t)-u^{\prime \prime}(0)=-\int_{0}^{1} \gamma(s) d s, \\
u^{\prime \prime}(t)=-\int_{0}^{1} \gamma(s) d s \leq 0 .
\end{gathered}
$$

Let $X=C^{2}[0,1]$ with $\|u\|=\max _{0 \leq t \leq 1}|u(t)|+\max _{0 \leq t \leq 1}\left|u^{\prime \prime}(t)\right|$. Obviously, $(X,\|\cdot\|)$ is a Banach space. Define the cone $P \subset X$ by

$$
P=\left\{u \in X\left|u(t) \geq 0, u^{\prime \prime}(t) \leq 0\right|\right\}, \quad P_{r}=\{u \in P \mid\|u\|<r, r>0\} .
$$

Obviously $P$ is a cone in $X$, and $P_{r}$ is a bounded open subset in $P$.

Definition 2.1 [1]. Let $P$ be a cone in a Banach space $X$. If for any $x \in X$ and $x^{+}, x^{-}$ $\in P$, writing $x=x^{+}+x^{-}$shows that $P$ is a reproducing cone.

Lemma 2.3. $P$ is a reproducing cone in $X$.

Proof. Suppose $u \in X$, so $u^{\prime \prime} \in C[0,1]$ and

$$
u^{\prime \prime}=u^{-}-u^{+},
$$

where $u^{-}=\min \left\{u^{\prime \prime}(t), 0\right\}, u^{+}=\min \left\{-u^{\prime \prime}(t), 0\right\}$. Obviously $u^{+}, u^{-} \in C[0,1]$ and $u^{+} \leq 0, u^{-}$ $\leq 0$. For (2.2), we get

$$
\begin{gathered}
u^{\prime}(t)=\int_{0}^{t} u^{-}(s) d s-\int_{0}^{t} u^{+}(s) d s+u^{\prime}(0), \\
u(t)=\int_{0}^{t} d s \int_{0}^{s} u^{-}(\tau) d \tau-\int_{0}^{t} d s \int_{0}^{s} u^{+}(\tau) d \tau+u^{\prime}(0) t+u(0) .
\end{gathered}
$$

If $u(0) \geq 0, u^{\prime}(0) t \geq 0$, let

$$
u_{1}=-\int_{0}^{t} d s \int_{0}^{s} u^{+}(\tau) d \tau+u^{\prime}(0) t+u(0), u_{2}=-\int_{0}^{t} d s \int_{0}^{s} u^{-}(\tau) d \tau .
$$

So $u_{1} \geq 0, u_{2} \geq 0$, then $u_{1}, u_{2} \in P$ and $u=u_{1}-u_{2}$.

If $u(0) \leq 0, u^{\prime}(0) t \leq 0$, let

$$
u_{1}=-\int_{0}^{t} d s \int_{0}^{s} u^{+}(\tau) d \tau, u_{2}=-\int_{0}^{t} d s \int_{0}^{s} u^{-}(\tau) d \tau-u^{\prime}(0) t-u(0) .
$$

So $u_{1} \geq 0, u_{2} \geq 0$, then $u_{1}, u_{2} \in P$ and $u=u_{1}-u_{2}$.

If $u(0) \geq 0, u^{\prime}(0) t \leq 0$, let

$$
u_{1}=-\int_{0}^{t} d s \int_{0}^{s} u^{+}(\tau) d \tau+u(0), \quad u_{2}=-\int_{0}^{t} d s \int_{0}^{s} u^{-}(\tau) d \tau-u^{\prime}(0) t .
$$


So $u_{1} \geq 0, u_{2} \geq 0$, then $u_{1}, u_{2} \in P$ and $u=u_{1}-u_{2}$.

If $u(0) \leq 0, u^{\prime}(0) t \geq 0$, let

$$
u_{1}=-\int_{0}^{t} d s \int_{0}^{s} u^{+}(\tau) d \tau+u^{\prime}(0) t, u_{2}=-\int_{0}^{t} d s \int_{0}^{s} u^{-}(\tau) d \tau-u(0)
$$

So $u_{1} \geq 0, u_{2} \geq 0$, then $u_{1}, u_{2} \in P$ and $u=u_{1}-u_{2}$.

Then $P$ is a reproducing cone in $X$.

Lemma 2.4 (Krein-Rutman) [8]. Let $K$ be a reproducing cone in a real Banach space $X$ and let $L: K \rightarrow K$ be a compact linear operator with $L(K) \subset K . r(L)$ is the spectral radius of $L$. If $r(L)>0$, then there is $\phi_{1} \in K \backslash\{0\}$ such that $L \phi_{1}=r(L) \phi_{1}$.

Lemma 2.5 [9]. Let $X$ be a Banach space, $P$ be a cone in $X$ and $\Omega(P)$ be a bounded open subset in $P$. Suppose that $A: \overline{\Omega(P)} \rightarrow P$ is a completely continuous operator. Then the following results hold

(1) If there exists $u_{0} \in P \backslash\{0\}$ such that $u \neq A u+\lambda u_{0}$, for any $u \in \partial \Omega(P), \lambda \geq 0$, then the fixed-point index $i(A, \Omega(P), P)=0$.

(2) If $0 \in \Omega(P), A u \neq \lambda u$, for any $u \in \partial \Omega(P), \lambda \geq 1$, then the fixed-point index $i(A$, $\Omega(P), P)=1$.

Define the operator $A: X \rightarrow X, L: X \rightarrow X$, by

$$
\begin{aligned}
& A u(t)=\int_{0}^{1} H(t, s) f\left(s, u(s), u^{\prime \prime}(s)\right) d s, \\
& L u(t)=\int_{0}^{1} H(t, s)\left(u(s)-u^{\prime \prime}(s)\right) d s,
\end{aligned}
$$

So $A: P \rightarrow P$ is completely continuous operator; $L: P \rightarrow P$ is a compact linear operator.

Lemma 2.6 [7]. Assume that $\left(H_{2}\right)$ holds, then choose $\delta \in\left(0, \frac{1}{2}\right)$, for all $t \in[\delta, 1$ $\delta], v, s \in[0,1]$, we have

$$
\begin{aligned}
& G(t, s) \geq \rho G(v, s), \\
& H(t, s) \geq \rho H(v, s),
\end{aligned}
$$

where $\rho=4 \delta^{2}(1-\delta)$.

Note: $r(L)$ is the spectral radius of $L . h=\min _{t \in[\delta, 1-\delta]} \int_{\delta}^{1-\delta} H(t, s) d s$, where $\delta \in\left(0, \frac{1}{2}\right)$. By Lemma 2.6, obviously $h>0$.

Lemma 2.7. Suppose conditions $\left(H_{1}\right),\left(H_{2}\right)$ hold, then $r(L)>0$. 
Proof. Take $u(t) \equiv 1$, then $u^{\prime \prime}(t)=0$, for any $t \in[\delta, 1-\delta]$ we get

$$
\begin{gathered}
L u(t) \geq \int_{\delta}^{1-\delta} H(t, s) d s \geq h>(0) . \\
L^{2} u(t) \geq \int_{\delta}^{1-\delta} H(t, s) L u(s) d s \geq h \int_{\delta}^{1-\delta} H(t, s) d s \geq h^{2}>0 .
\end{gathered}
$$

Repeating the process gives

$$
L^{k} u(t) \geq h^{k} .
$$

So, we get $\left\|L^{k}\right\| \geq h^{k}, r(L)=\lim _{k \rightarrow \infty}\left\|L^{k}\right\| \frac{1}{k} \geq h>0$. The proof is completed.

By Lemma 2.4, then there is $\phi_{1} \in P \backslash\{0\}$ such that $L \phi_{1}=r(L) \phi_{1}$.

\section{Main results}

In the following, we use the notation:

$$
\begin{gathered}
\bar{f}(u, v)=\sup _{t \in[0,1] \backslash E} f(t, u, v), \quad f(u, v)=\inf _{t \in[0,1] \backslash E} f(t, u, v), \\
f^{\infty}=\max \left\{\lim _{u \rightarrow \infty} \sup \left\{\sup _{v \in R^{-}} \frac{\bar{f}(u, v)}{u-v}\right\}, \quad \lim _{v \rightarrow-\infty} \sup \left\{\sup _{u \in R^{+}} \frac{\bar{f}(u, v)}{u-v}\right\}\right\}, \\
f_{0}^{d}=\max \left\{\lim _{u \rightarrow 0+} \inf \left\{\inf _{v \in[-d, 0]} \frac{f(u, v)}{u-v}\right\}, \quad \lim _{v \rightarrow 0-} \inf \left\{\inf _{u \in[0, d]} \frac{f(u, v)}{u-v}\right\}\right\},
\end{gathered}
$$

where $E$ is a fixed subset of $[0,1]$ of measure zero, $d>0$.

Lemma 3.1. Suppose

$$
0 \leq f^{\infty}<\mu,
$$

where $\mu=1 / r(L)$, then there exists $R_{0}>0$ such that $i\left(A, P_{n}, P\right)=1$ for each $r>R_{0}$.

Proof. Let $\varepsilon>0$ satisfy $f^{\circ} \leq \mu-\varepsilon$, then there exist $r_{1}>0$ such that

$$
f(t, u, v) \leq(\mu-\varepsilon)(u-v),
$$

for all $u>r_{1}$ or $v<-r_{1}$ and a.e. $t \in[0,1]$.

By $\left(H_{1}\right)$, there exists $\varphi_{r_{1}} \in L^{\infty}[0,1]$ such that

$$
0 \leq f(t, u, v) \leq \varphi_{r_{1}}(t)
$$

for all $(u, v) \in\left[0, r_{1}\right] \times\left[-r_{1}, 0\right]$ and a.e. $t \in[0,1]$. Hence, we have

$$
f(t, u, v) \leq(\mu-\varepsilon)(u-v)+\varphi_{r_{1}}(t)
$$

for all $u \in \mathrm{R}^{+}, v \in R^{-}$and a.e. $t \in[0,1]$.

Since $\frac{1}{\mu}$ is the spectrum radius of $L$. It follows from

$$
\begin{aligned}
& \left(\frac{1}{\mu-\varepsilon} I-L\right)^{-1}=\sum_{n=0}^{\infty}(\mu-\varepsilon)^{n+1} L^{n},(I /(\mu-\varepsilon)-L)^{-1} \text { exists, let } \\
& C=\left\|\int_{0}^{1} H(t, s) \varphi_{r_{1}}(s) d s\right\|, R_{0}=\left\|\left(\frac{1}{\mu-\varepsilon} I-L\right)^{-1} \frac{C}{\mu-\varepsilon}\left(\frac{3}{2}-\frac{1}{2} t^{2}\right)\right\| .
\end{aligned}
$$


For $r>R_{0}$, by Lemma 2.5 we will prove

$A u \neq \lambda u$,

for each $u \in \partial P_{r}$ and $\lambda \geq 1$.

In fact, if not, there exist $u_{0} \in \partial P_{r}$ and $\lambda_{0} \geq 1$ such that $A u_{0}=\lambda_{0} u_{0}$.

Together with (3.2) implies

$$
\begin{gathered}
u_{0}(t) \leq A u_{0}(t) \leq \int_{0}^{1} H(t, s)\left[(\mu-\varepsilon) u_{0}(s)+\varphi_{r_{1}}(t)\right] d s \\
\left.\leq \int_{0}^{1} H(t, s)(\mu-\varepsilon)\left[u_{0}(s)-v_{0}(s)\right)+\varphi_{r_{1}}(s)\right] d s .
\end{gathered}
$$

So

$$
\begin{gathered}
u_{0}(t) \leq(\mu-\varepsilon) L u_{0}(t)+C, \\
u_{0}^{\prime \prime}(t) \geq \lambda_{0} u_{0}^{\prime \prime}(t)=\left(A u_{0}(t)\right)^{\prime \prime} \geq(\mu-\varepsilon)\left(L u_{0}(t)\right)^{\prime \prime}-C .
\end{gathered}
$$

Then

$$
\left(\frac{1}{\mu-\varepsilon} I-L\right) u_{0}(t) \leq \frac{C}{\mu-\varepsilon}\left(\frac{3}{2}-\frac{1}{2} t^{2}\right),\left(\left(\frac{1}{\mu-\varepsilon} I-L\right) u_{0}(t)\right)^{\prime \prime} \geq\left(\frac{C}{\mu-\varepsilon}\left(\frac{3}{2}-\frac{1}{2} t^{2}\right)\right)^{\prime \prime} .
$$

So

$$
\frac{C}{\mu-\varepsilon}\left(\frac{3}{2}-\frac{1}{2} t^{2}\right)-\left(\frac{1}{\mu-\varepsilon} I-L\right) u_{0}(t) \in P
$$

Then

$$
\begin{aligned}
u_{0}(t) \leq\left(\frac{I}{\mu-\varepsilon}-L\right)^{-1} \frac{C}{\mu-\varepsilon}\left(\frac{3}{2}-\frac{1}{2} t^{2}\right), u_{0}^{\prime \prime}(t) & \geq\left[\left(\frac{I}{\mu-\varepsilon}-L\right)^{-1} \frac{C}{\mu-\varepsilon}\left(\frac{3}{2}-\frac{1}{2} t^{2}\right)\right]^{\prime \prime}, \\
\left\|u_{0}(t)\right\| \leq R_{0} & <r .
\end{aligned}
$$

This is a contradiction. By Lemma 2.5 (2), we get that $i\left(A, P_{r}, P\right)=1$ for each $r>R_{0}$. The proof is completed.

Lemma 3.2. Suppose there exists $d>0$ such that

$$
\mu<f_{0}^{d} \leq \infty .
$$

Then there exists $\rho_{0}>0$ and $d \geq \rho_{0}$ such that for each $\rho \in\left(0, \rho_{0}\right]$, if $u \neq A u$ for $u \in$ $\partial P \rho$, then $i\left(A, P_{\rho}, P\right)=0$.

Proof. Let $\varepsilon>0$ satisfy $f_{0}^{d} \geq \mu+\varepsilon$, there exist $d \geq \rho_{0}>0$ such that

$$
f(t, u, v) \geq(\mu+\varepsilon)(u-v),
$$

for $u \in\left[0, \rho_{0}\right], v \in\left[-\rho_{0}, 0\right]$ and a.e. $t \in[0,1]$.

Let $\rho \in\left(0, \rho_{0}\right]$, by Lemma 2.5 (1), we prove that: $u \neq A u+\lambda \phi_{1}$ for all $u \in \partial P \rho, \lambda>0$, where $\phi_{1} \in P \backslash\{0\}$ is the eigenfunction of $L$ corresponding to the eigenvalue $\frac{1}{\mu}$. In fact, if not, there exist $u_{0} \in \partial P_{\rho}, \lambda_{0}>0$ such that $u_{0}=A u_{0}+\lambda_{0} \phi_{1}$. This implies

$$
u_{0} \geq \lambda_{0} \varphi_{1} \text { and } u_{0}^{\prime \prime} \leq \lambda_{0} \varphi_{1}^{\prime \prime} .
$$


Let: $\lambda^{*}=\sup \left\{\lambda \mid u_{0} \geq \lambda \varphi_{1}, u_{0}^{\prime \prime} \leq \lambda \varphi_{1}^{\prime \prime}\right\}$.

So $0<\lambda_{0}<\lambda^{*}<\infty$ and $u_{0} \geq \lambda^{*} \varphi_{1}, u_{0}^{\prime \prime} \leq \lambda^{*} \varphi_{1}^{\prime \prime}$. Then, $u_{0}-\lambda^{*} \phi_{1} \in P$.

For $L(P) \subset P$, we get

$$
\mu L u_{0} \geq \lambda^{*} \mu L \varphi_{1}=\lambda^{*} \varphi_{1}, \quad \mu\left(L u_{0}\right)^{\prime \prime} \leq \lambda^{*} \mu\left(L \varphi_{1}\right)^{\prime \prime}=\lambda^{*} \varphi_{1}^{\prime \prime} .
$$

By (3.4), we get

$$
\begin{gathered}
A u_{0}=\int_{0}^{1} H(t, s) f\left(s, u_{0}(s), u_{0}^{\prime \prime}(s)\right) d s \geq(\mu+\varepsilon) L u_{0} . \\
\left(A u_{0}\right)^{\prime \prime} \leq(\mu+\varepsilon)\left(L u_{0}\right)^{\prime \prime} .
\end{gathered}
$$

So, we know

$$
\begin{gathered}
u_{0}=A u_{0}+\lambda_{0} \varphi_{1} \geq(\mu+\varepsilon) L u_{0}+\lambda_{0} \varphi_{1} \geq\left(\lambda^{*}+\lambda_{0}\right) \varphi_{1} . \\
\left(u_{0}\right)^{\prime \prime}=\left(A u_{0}\right)^{\prime \prime}+\lambda_{0} \varphi_{1}^{\prime \prime} \leq(\mu+\varepsilon)\left(L u_{0}\right)^{\prime \prime}+\lambda_{0} \varphi_{1}^{\prime \prime} \leq\left(\lambda^{*}+\lambda_{0}\right) \varphi_{1}^{\prime \prime} .
\end{gathered}
$$

which contradicts the definition of $\lambda^{*}$.

Lemma 3.3. Suppose there is $\rho_{1}>0$ such that

$$
f(t, u, v) \leq d_{1} \rho_{1}
$$

for $u \in\left[0, \rho_{1}\right]$ and $v \in\left[-\rho_{1}, 0\right]$ a.e. $t \in[0,1]$, where $d_{1}=\frac{1}{\left\|\int_{0}^{1} H(t, s) d s\right\|}$, if $A u \neq u$ for $u \in \partial P_{\rho_{1}}$, then $i\left(A, P_{\rho_{1}}, P\right)=1$.

Proof. Suppose $u \in \partial P_{\rho_{1}}$, by Lemma 2.2, we get

$$
\begin{aligned}
\|A u\| & =\max _{0 \leq t \leq 1} A u(t)-\min _{0 \leq t \leq 1}(A u(t))^{\prime \prime} \\
& =\max _{0 \leq t \leq 1} \int_{0}^{1} H(t, s) f\left(t, u(t), u^{\prime \prime}(t)\right) d s+\max _{0 \leq t \leq 1}\left(\int_{0}^{1} H(t, s) f\left(t, u(t), u^{\prime \prime}(t)\right) d s\right)^{\prime \prime} \\
& \leq d_{1} \rho_{1}\left[\max _{0 \leq t \leq 1} \int_{0}^{1} H(t, s) d s+\max _{0 \leq t \leq 1}\left(\int_{0}^{1} H(t, s) d s\right)\right] \leq \rho_{1} .
\end{aligned}
$$

That is $A u \neq \lambda u$ for each $u \in \partial P_{\rho_{1}}, \lambda>1$. If $A u \neq u$ for $u \in \partial P_{\rho_{1}}$, by Lemma 2.5, then $i\left(A, P_{\rho_{1}}, P\right)=1$.

Lemma 3.4. Suppose there is $\rho_{2}>0$ such that

$$
f(t, u, v) \geq d_{2} \rho_{2},
$$

$$
\begin{aligned}
& \text { for } u \in\left[\begin{array}{ll}
0, & \rho 2
\end{array}\right] \text { and } v \in\left[\begin{array}{ll}
-\rho 2, & 0
\end{array}\right] \text { a.e. } t \in\left[\begin{array}{ll}
0, & 1
\end{array}\right] \text {, where } \\
& d_{2}=\frac{1}{\min _{t \in[\delta, 1-\delta]} \int_{0}^{1} H(t, s) d s-\max _{t \in[\delta, 1-\delta]}\left(\int_{0}^{1} H(t, s) d s\right)^{\prime \prime}} \text {. If } A u \neq u \text { for } u \in \partial P_{\rho_{2}} \text {, then } \\
& i\left(A, P_{\rho_{2}}, P\right)=0 .
\end{aligned}
$$


Proof. For $u \in \partial P_{\rho_{2}}, t \in[\delta, 1-\delta]$, by Lemma 2.2, we get

$$
\begin{aligned}
A u+(A u)^{\prime \prime} & =\int_{0}^{1} H(t, s) f\left(t, u(t), u^{\prime \prime}(t)\right) d s+\left(\int_{0}^{1} H(t, s) f\left(t, u(t), u^{\prime \prime}(t)\right) d s\right)^{\prime \prime} \\
& \geq d_{2} \rho_{2}\left[\int_{0}^{1} H(t, s) d s+\left(\int_{0}^{1} H(t, s) d s\right)\right] \geq \rho_{2}
\end{aligned}
$$

This implies that $u \neq A u+\lambda \phi$ for each $u \in \partial P_{\rho_{2}}, \lambda>0$, where $\phi \in P \backslash\{0\}$ is the eigenfunction of $L$ corresponding to $r(L)$. Suppose $u \neq A u$ for $u \in \partial P_{\rho_{2}}$, by Lemma 2.5, then $i\left(A, P_{\rho_{2}}, P\right)=0$.

Theorem 3.1. The boundary value problem (1.1) has at least one positive solution if one of the following conditions holds.

(C1) There exists $d>0$ such that (3.3) and (3.1) hold.

(C2) There exists $d>0, \rho_{1}>0$ such that (3.3) and (3.5) hold.

(C3) There exists $\rho_{2}>0$ such that (3.6) and (3.1) hold.

(C4) There exists $\rho_{1}, \rho_{2}>0$ with $0<\rho_{2}<\rho_{1} d_{1} / d_{2}$ such that (3.5) and (3.6) hold.

Proof. When condition (C1) holds, by Lemma 3.1 and $0 \leq f^{\infty}<\mu$, we get that there exists $r>0$ such that $i\left(A, P_{r}, P\right)=1$. It follows from Lemma 3.2 and $\mu<f_{0}^{b} \leq \infty$, then there exists $0<\rho<\min \{r, d\}$ such that either there exists $u \in \partial P_{\rho}$ that $i\left(A, P_{\rho}, P\right)=0$ or $u=A u$. So BVP (1.1) has at least one positive solution $u \in P$ with $\rho \leq\|u\|<r$.

When one of other conditions holds, the results can be proved similarly.

\section{Acknowledgements}

The project is supported by the Natural Science Foundation of China (10971045) and the Natural Science Foundation of Hebei Province (A2009000664, A2011208012). The research item financed by the talent training project funds of Hebei Province. The authors would like to thank the referee for helpful comments and suggestions.

\section{Author details}

${ }^{1}$ College of Electrical Engineering and Information, Hebei University of Science and Technology, Shijiazhuang, 050018, Hebei, PR China ${ }^{2}$ College of Sciences, Hebei University of Science and Technology, Shijiazhuang, 050018, Hebei, PR China

\section{Authors' contributions}

The authors declare that the study was realized in collaboration with same responsibility. All authors read and approved the final manuscript.

\section{Competing interests}

The authors declare that they have no competing interests.

Received: 3 November 2011 Accepted: 26 March 2012 Published: 26 March 2012

\section{References}

1. Webb, JRL, Lan, KQ: Eigenvalue criteria for existence of multiple positive solutions of nonlinear boundary value problems of local and nonlocal type. Topolog Methods Nonlinear Anal J Juliusz Schauder Center. 27, $91-115$ (2006)

2. Jiang, WH: The existence of positive solutions for second-order multi-point BVPs with the first derivative. J Comput Appl Math. 225, 387-392 (2009). doi:10.1016/j.cam.2008.07.043

3. Jiang, WH: Eigenvalue criteria for existence of multiple positive solutions of high-order nonlinear BVPs. Nonlinear Anal. 69, 295-303 (2008). doi:10.1016/j.na.2007.05.020

4. Webb, JRL: Nonlocal conjugate type boundary value problems of higher order. Nonlinear Anal. 71, $1933-1940$ (2009). doi:10.1016/j.na.2009.01.033

5. Hao, XN, Liu, LS, Wu, YH, Sun, Q: Positive solutions for nonlinear nth-order singular eigenvalue problem with nonlocal conditions. Nonlinear Anal. 73, 1653-1662 (2010). doi:10.1016/j.na.2010.04.074 
6. Guo, YP, Ge, WG: Positive solutions for three-point boundary value problems with dependence on the first order derivatives. J Math Anal Appl. 290, 291-301 (2004). doi:10.1016/j.jmaa.2003.09.061

7. Zhao, JF, Wang, PG, Ge, WG: Existence and nonexistence of positive solutions for a class of third order BVP with integral boundary conditions in Banach spaces. Commun Nonlinear Sci Numer Simulat. 16, $402-413$ (2011). doi:10.1016/ j.cnsns.2009.10.011

8. Nussbaum, RD: Eigenvectors of nonlinear positive operators and the linear Krein-Rutman theorem, Fixed Point Theory. Lecture Notes Math. 886, 309-330 (1981). doi:10.1007/BFb0092191

9. Guo, D, Lakshmikantham, V: Nonlinear Problems in Abstract Cones. Academic Press, New York (1988)

doi:10.1186/1687-2770-2012-34

Cite this article as: Guo et al.: Positive solutions for the third-order boundary value problems with the second derivatives. Boundary Value Problems 2012 2012:34

Submit your manuscript to a SpringerOpen ${ }^{\circ}$ journal and benefit from:

- Convenient online submission

- Rigorous peer review

- Immediate publication on acceptance

- Open access: articles freely available online

- High visibility within the field

- Retaining the copyright to your article

Submit your next manuscript at $\boldsymbol{\nabla}$ springeropen.com 